\title{
Humanização na Unidade de Terapia Intensiva Pediátrica: facilidades e dificuldades da equipe de enfermagem
}

\author{
Umanization in the Pediatric Intensive Care Unit: facilities and difficulties of the nursing team \\ Humanización en la Unidad de Cuidados Intensivos Pediátricos: instalaciones y dificultades del \\ equipo de enfermería
}

Recebido: 01/12/2021 | Revisado: 06/12/2021 | Aceito: 10/12/2021 | Publicado: 18/12/2021

\author{
Rosi Muller \\ ORCID: https://orcid.org/0000-0002-5931-3234 \\ Universidade Federal do Rio Grande, Brasil \\ E-mail: muller-ro@hotmail.com \\ Giovana Calcagno Gomes \\ ORCID: https://orcid.org/0000-0002-2464-1537 \\ Universidade Federal do Rio Grande, Brasil \\ E-mail:giovanacalcagno@furg.br \\ Pâmela Kath de Oliveira Nörnberg \\ ORCID: https://orcid.org/0000-0002-5931-3234 \\ Universidade Federal do Rio Grande, Brasil \\ E-mail: Pamelakathpko@yahoo.com.br \\ Daiani Modernel Xavier \\ ORCID: https://orcid.org/0000-0003-2376-6474 \\ Universidade Federal do Rio Grande, Brasil \\ E-mail: Daiamoder@gmail.com \\ Alex Sandra Avila Minasi \\ ORCID: https://orcid.org/0000-0003-4196-5469 \\ Universidade Federal do Rio Grande, Brasil \\ E-mail: alexsandra@furg.br \\ Ana Cláudia Fortuna da Silva \\ ORCID: https://orcid.org/0000-0002-2093-2599 \\ Prefeitura Municipal de Monte Alegre, Brasil \\ E-mail: ana-claudia-1995@hotmail.com
}

\begin{abstract}
Resumo
Objetivo: Conhecer as facilidades e dificuldades da equipe de enfermagem na prestação de um cuidado humanizado na Unidade de Terapia Intensiva Pediátrica. Metodologia: Pesquisa descritiva e exploratória de cunho qualitativo no segundo semestre de 2021 na Unidade de Terapia Intensiva Pediátrica de um Hospital no sul do Brasil. Participaram 17 profissionais da equipe de enfermagem. A coleta de dados foi realizada por meio de entrevistas semiestruturadas. Os dados foram analisados pela técnica de Análise Temática. Resultados: Citaram como facilidades para garantir uma assistência humanizada o reduzido número de pacientes do setor, o trabalho em equipe multidisciplinar, a boa remuneração e a boa comunicação com a liderança, a colaboração e o comprometimento da equipe e ter uma brinquedoteca no hospital. Como dificuldades referiram, alguns referiram que não existem, o pouco tempo e falta de profissionais, a sobrecarga de trabalho, o convívio com o país das crianças internadas, a falta de espaço e conforto para os pais na unidade, a prestação de um cuidado mais técnico e de uma assistência mecanicista e as dificuldades individuais de cada pessoa em trabalhar com crianças em estado crítico. Conclusão: A humanização da assistência faz parte da preocupação dos profissionais atuantes na unidade. A equipe de enfermagem considera a pratica humanizada importante, enfrentando desafios para cuidar a criança em estado crítico e sua família.

Palavras-chave: Humanização da assistência hospitalar; Unidades de Terapia Intensiva Pediátrica; Cuidado de enfermagem; Criança hospitalizada.
\end{abstract}

\begin{abstract}
Objective: To understand the facilities and difficulties of the nursing team in providing humanized care in the Pediatric Intensive Care Unit. Methodology: Descriptive and exploratory qualitative research in the second half of 2021 in the Pediatric Intensive Care Unit of a Hospital in southern Brazil. 17 professionals from the nursing team participated. Data collection was carried out through semi-structured interviews. Data were analyzed using the Thematic Analysis technique. Results: They cited the reduced number of patients in the sector, multidisciplinary teamwork, good remuneration and good communication with the leadership, collaboration and commitment of the team and having a toy library in the hospital as facilities to ensure humanized care. As difficulties mentioned, some mentioned that they do not exist, little time and lack of professionals, work overload, living with the country of
\end{abstract}


hospitalized children, lack of space and comfort for parents in the unit, providing more care technical and mechanistic assistance and the individual difficulties of each person in working with children in critical condition. Conclusion: The humanization of care is part of the concern of professionals working in the unit. The nursing team considers humanized practice to be important, facing challenges in caring for critically ill children and their families.

Keywords: Humanization of assistance; Intensive Care Units, Pediatric; Nursing care; Child, hospitalized.

\section{Resumen}

Objetivo: Conocer las facilidades y dificultades del equipo de enfermería para brindar cuidados humanizados en la Unidad de Cuidados Intensivos Pediátricos. Metodología: Investigación cualitativa descriptiva y exploratoria en el segundo semestre de 2021 en la Unidad de Cuidados Intensivos Pediátricos de un Hospital del sur de Brasil. Participaron 17 profesionales del equipo de enfermería. La recolección de datos se realizó mediante entrevistas semiestructuradas. Los datos se analizaron mediante la técnica de Análisis Temático. Resultados: Citaron el reducido número de pacientes del sector, el trabajo en equipo multidisciplinar, la buena retribución y la buena comunicación con el liderazgo, la colaboración y compromiso del equipo y disponer de ludoteca en el hospital como facilidades para asegurar una atención humanizada. Como dificultades mencionadas, algunos mencionaron que no existen, poco tiempo y falta de profesionales, sobrecarga de trabajo, convivencia con el país de los niños hospitalizados, falta de espacio y comodidad para los padres en la unidad, brindar mayor atención técnica y asistencia mecanicista y la Dificultades individuales de cada persona para trabajar con niños en estado crítico. Conclusión: La humanización del cuidado es parte de la preocupación de los profesionales que laboran en la unidad. El equipo de enfermería considera importante la práctica humanizada, enfrentando desafíos en el cuidado de niños críticamente enfermos y sus familias.

Palabras clave: Humanización de la asistencia; Unidades de Cuidados Intensivos Pediátricos; Atención de enfermería; Niño hospitalizado.

\section{Introdução}

A UTIP é um local que se destina às crianças que necessitam de cuidados intensivos por algum motivo (Pêgo; Barros, 2017). Podem ser admitidas crianças com uma série de afecções, as quais devem cumprir critérios de elegibilidade específicos que envolvem gravidade e risco de vida, incluindo-se doença pulmonar ou de vias respiratórias, doença cardiovascular, doença neurológica, doença oncológica ou hematológica ou sangramento ativo, alteração metabólica ou eletrolítica de grande monta, doença gastrointestinal instável, pós-operatório que necessita de monitoração e intervenção ou ainda doenças de outros sistemas ou múltiplos sistemas (Brasil, 2017).

Para Gequelin et al. (2014) a UTIP é um ambiente de alta tecnologia, que envolve a disponibilização de diversos recursos para fornecer a melhor assistência ao paciente pediátrico. Caracteriza-se como um local crítico de internação de pacientes em grau grave de saúde, que demandam atenção profissional constante e especializada, materiais específicos e tecnologias fundamentais no que se refere à realização do diagnóstico, monitorização e terapia.

Pozzati et al. (2017) afirmam que desde a criação das UTIP o objetivo primordial é salvar vidas de crianças em estado grave de saúde e com risco iminente de morte. Destarte, mediante o avanço tecnológico, das ciências médicas e das técnicas procedimentais, isso vem sendo possível, mas, muitas vezes, salvar ou estender a vida destas crianças envolve procedimentos traumáticos e invasivos.

Segundo Rodrigues \& Calegari (2016), nessas unidades de cuidado intensivo imersas em um contexto em que a prática é mecanizada e especializada, é indispensável uma reflexão sobre o verdadeiro sentido da assistência como forma de cuidado, que deve ser realizada a partir da relação com a humanização, partindo da hipótese de que o paciente tem o direito de se satisfazer com o serviço por meio do atendimento de qualidade. Para atingir o sucesso dessa relação, todos os profissionais de saúde precisam fortalecer o contato, o diálogo, o vínculo e valorizar os pacientes, pois ao conversar com os mesmos e ouvir suas necessidades, viabilizam a resolubilidade e o cuidado integral.

$\mathrm{Na}$ assistência pediátrica encontra-se ainda a crença de que a criança não é madura o suficiente para compreender o processo de doença e hospitalização, e desse modo, os tratamentos são realizados, muitas vezes, sem explicação correta e contra a vontade da família e das próprias crianças. Não raramente, alguns familiares querem ocultar informações à criança, relativas à internação hospitalar, seus procedimentos e tratamentos, acreditando que isso vai causar efeitos indesejáveis 
(Menezes, 2010; Guerra et al., 2019). Observa-se que isso pode acarretar na criança um sentimento de desconfiança, fazendo com que a vivência nesse ambiente seja mais negativa ainda.

O ambiente hospitalar passa a ser entendido pela criança como um local potencialmente ameaçador e perigoso, uma vez que é lá que procedimentos invasivos e dolorosos são realizados. Ao promover o afastamento da criança dos entes queridos, dos brinquedos e das brincadeiras, além do isolamento e da separação de seu ambiente habitual, a vivência hospitalar tende a ser potencialmente traumática. Logo, a criança que já se encontra bastante fragilizada pela doença necessita encontrar maneiras para externar seus sentimentos, de forma a minimizar seus medos e angústias (Sossela \& Sager, 2017).

No período da internação, além do saber tecnológico e do conhecimento estruturado dos profissionais, a formação do vínculo, o acolhimento, a compreensão e a confiança ajudam para ambientar a criança na unidade (Pontes et al., 2014; Sampaio et al., 2017).

Estudo de Santos et al. (2020) objetivou compreender a percepção da criança hospitalizada sobre sua vivência no ambiente de uma UTIP e evidenciou aspectos importantes. Os resultados apontaram que a criança hospitalizada percebe que ficar restrita ao leito é algo entediante por ter que permanecer "preso" a cama, estando a maior parte do tempo conectado a fios de equipamentos para monitorização, não permitindo que seu corpo esteja livre para se mover. Há relato da impossibilidade de fazer as atividades com a qual está habituada, tornando a permanência no setor ainda mais difícil.

Além disso, a constante manipulação de diferentes profissionais, inúmeros exames realizados dentro e fora do setor, procedimentos de enfermagem, dentre outros, interrompe o descanso das crianças. Ademais, o intenso barulho gerado pelos equipamentos e a alta circulação de pessoas no ambiente, bem como o excesso de claridade, prejudica o conforto, sono e o repouso. Outros pontos expressos que demonstram sofrimento no ambiente da UTIP foram o relato de solidão e de dor e demais sintomas relacionados à patologia ou procedimentos realizados (Santos et al., 2020).

A humanização na UTIP atualmente envolve desde o ambiente físico até os relacionamentos entre os profissionais de saúde, pacientes e familiares. A humanização e sua filosofia vêm ganhando espaço no contexto das UTIP, inclusive provocando mudanças na sua forma de percepção, fazendo com que este setor hospitalar seja compreendido como um local que oportuniza a recuperação dos pacientes e não como um lugar destinado somente a pacientes com poucas chances de sobrevivência (Villa et al., 2017).

Devido à preocupação com o cuidado e a atenção as pessoas hospitalizadas o MS criou no ano de 2000 o Programa Nacional de Humanização da Assistência Hospitalar (PNHAH). Um programa transformador, que pretendia lançar a ideia de humanização nas práticas de saúde e aperfeiçoar a qualidade e a eficiência dos serviços disponibilizados a toda população. Em 2003, o MS, modificou esse programa e lançou a PNH com o objetivo de que a ideia da humanização deixasse de ser vista apenas no ambiente hospitalar e passasse a ser adotada na rotina de toda a rede do SUS (Machado \& Soares, 2016).

Humanizar o cuidado na UTIP exige uma transformação de comportamento e de atitudes da equipe de saúde em relação às crianças e seus familiares. Todos os profissionais que assistem direta ou indiretamente as crianças são os reais responsáveis por realizar a humanização, visto que a compreensão dos profissionais a respeito do tema possibilita que o mesmo seja colocado em prática da melhor forma possível e alcançando a finalidade proposta. A mudança de comportamento é difícil, principalmente quando se trata de UTIP, onde a rotina diária e a complexidade dos cuidados causam nos profissionais muitas reflexões, como o duelo entre a vida e a morte, sucesso e derrota, processo de tomada de decisões e questões éticas, prejudicando, deste modo, a realização do cuidado humanizado (Santos et al., 2018).

Portanto, diante do exposto a questão norteadora do presente estudo foi qual o significado do cuidado humanizado na percepção da equipe de enfermagem na Unidade de Terapia Intensiva Pediátrica? Nesse sentido, este estudo objetivou conhecer as facilidades e dificuldades da equipe de enfermagem na prestação de um cuidado humanizado na Unidade de Terapia Intensiva Pediátrica. 


\section{Metodologia}

Trata-se de uma pesquisa exploratória descritiva, com abordagem qualitativa. Segundo Minayo (2010), a pesquisa qualitativa trabalhar o universo de significados, motivos, aspirações, crenças, valores e atitudes. Desta forma, permite que o autor se envolva diretamente na situação e possibilita através da convivência e interação, observar os agentes no seu cotidiano (Minayo, 2010). A pesquisa foi realizada na UTIP de um Hospital Universitário do sul do Brasil (HU), local que além de realizar a assistência à saúde, também desenvolve projetos e ações de ensino, pesquisa e extensão. É referência no atendimento materno-infantil, possibilitando que acadêmicos de diversos cursos possam realizar atividades práticas de estágio, dentre eles a enfermagem, medicina, psicologia e educação física, incluindo a Residência Integrada Multiprofissional Hospitalar com ênfase na Atenção à Saúde Cardiometabólica do Adulto (RIMHAS).

A Unidade de Terapia Intensiva Pediátrica (UTIP) é composta por dois enfermeiros por turno de serviço, além de cinco técnicos de enfermagem e um enfermeiro gerencial. Suas acomodações são compostas por 10 leitos destinados a pacientes com idade entre 28 dias a 14 anos que estão em estado crítico. Ainda, uma enfermaria com cinco leitos, e outra com quatro leitos. Além, de um leito de isolamento, sala para uso da equipe multiprofissional, sala da secretária, sala de reuniões, sala destinada a comunicação com os pais, copa, sala de conforto médico, sala de conforto de enfermagem, expurgo, uma sala de medicação, uma sala para guarda de materiais e um almoxarifado.

Compuseram o corpo do estudo enfermeiros que atuavam no setor no período de coleta de dados, que atenderem ao critério de inclusão: trabalhar na unidade há pelo menos um mês. Como critério de exclusão estar de férias ou licença saúde no período da realização da coleta de dados. A UTIN possui 29 profissionais na equipe de enfermagem e todos foram convidados a participar do estudo.

A coleta dos dados foi realizada no segundo semestre de 2021 por meio de entrevistas semiestruturadas. Os participantes foram questionados acerca da sua percepção sobre a assistência de enfermagem humanizada na UTIP. Foi marcado dia e hora para a realização da entrevista, única com cada participante, realizadas na sala de reuniões da UTIP. As entrevistas foram gravadas e transcritas para análise.

Os dados foram analisados pela técnica de Análise de Conteúdo (AC) de Bardin (2011), que compreende um conjunto de operações adequadas para interpretar o conteúdo de uma mensagem e propicia ao pesquisador conhecer o que está por traz das palavras. A AC apresenta as seguintes fases: pré-análise; exploração do material e o tratamento dos resultados: inferência e interpretação (Bardin, 2011).

Foram atendidos todos princípios éticos da pesquisa envolvendo seres humanos, conforme preconiza a Resolução 510/2016 (Brasil, 2016). Autorização da Gerência de Ensino e Pesquisa (GEP) e do Comitê de Pesquisa da Escola de Enfermagem (COMPESQ) e do Comitê de Ética da FURG (CEP/FURG) e com o parecer favorável de CAAE número 04098118.2.0000.5324 ( $\mathrm{n}^{\circ}$ 35/2019). As falas dos participantes foram identificadas pelas letras E (enfermeiro) e TE (técnico de enfermagem), seguida do número da entrevista, com vistas a garantir o seu anonimato, além da assinatura do Termo de Consentimento Livre e Esclarecido em duas vias.

\section{Resultados}

Participaram do estudo 17 profissionais da equipe de enfermagem da Unidade de Terapia Intensiva Pediátrica, dentre eles 10 enfermeiros e sete técnicos de enfermagem. Os profissionais tinham entre 24 e 49 anos de idade, sendo a maioria do sexo feminino, 15 mulheres e dois homens. Destes, oito participantes não possuem filhos, quatro participantes possuem um filho e cinco participantes possuem dois filhos. Em relação ao tempo de atuação na UTIP, variou entre tempo máximo de dois anos e mínimo de profissionais com menos de um ano no setor. Em relação ao tempo de formação dos profissionais variou entre 24 e quatro anos, destes, dez profissionais possuíam cursos de pós-graduação, nas áreas: Enfermagem do Trabalho; 
Urgência e Emergência; Enfermagem Intensiva; Gestão; Docência; Saúde Pública; UTI adulto, pediátrica e neonatal; UTI adulto e pediátrica; Enfermagem hemato-oncológica; Intensivismo pediátrico; UTI pediátrica e neonatal e mestrado, além de Pós-técnico de qualificação em atendimento pediátrico.

As seguintes categorias emergiram através da análise dos dados: Facilidades identificadas pela equipe de enfermagem para garantir uma assistência humanizada na UTIP e Dificuldades encontradas pela equipe de enfermagem para garantir a assistência humanizada na UTIP.

\subsection{Facilidades identificadas pela equipe de enfermagem para garantir uma assistência humanizada na UTIP}

As facilidades são os fatores que favorecem a realização da assistência humanizada que pela equipe de enfermagem. O fato da Unidade ter poucos pacientes (no máximo 05), ser uma unidade pequena, ter uma boa carga horária e o fato de cada profissional ficar com apenas uma criança comparado a outros setores foram referidos pelos participantes como facilitadores para a realização de uma assistência humanizada.

Questão do número de pessoal, esse tipo de problema aqui a gente não enfrenta. Acho que isso é uma grande facilidade. (E6)

A gente não trabalha com muitos pacientes. Então, a gente consegue prestar mais atenção. A maior facilidade aqui é o número de pacientes reduzidos comparado aos outros setores. (E7)

Outra facilidade destacada pela maioria dos profissionais é o trabalho com uma equipe multidisciplinar, formada por fisioterapeutas, fonoaudiólogos, nutricionistas, terapeutas ocupacionais, psicólogos, médicos e enfermeiras. Essa equipe faz com que o cuidado seja integral e que a assistência se torne mais humanizada dentro da UTIP. Destacaram que a troca de experiências entre os membros da equipe favorece a humanização da assistência no setor.

A equipe multiprofissional, acho que isso é uma facilidade. Tu ter à mão uma terapeuta ocupacional, você dispor de um fisioterapeuta de plantão ali. É a garantia de um cuidado integral. Se for preciso encaminhar para o psicólogo ele se envolve. Também temos nutricionistas, fonoaudióloga. (E1)

Com a equipe multiprofissional a gente faz aquele acolhimento completo. [...]Então, eu acho que com relação de você ter essa equipe multiprofissional faz com que as coisas se tornem mais humanizadas dentro do hospital. (TE4)

A equipe multiprofissional aqui eu acho que é bem disponível: nutricionista, fonoaudióloga, fisioterapeuta, até o relacionamento entre os profissionais também é bem legal, bem recíproco também. (E10)

A remuneração salarial boa foi referida pelos participantes como um facilitador, pois faz com que os profissionais tenham apenas um emprego e não tenham interesse em procurar outro serviço.

O incentivo salarial influencia bastante, pelo menos aqui a maioria do pessoal trabalha apenas em um emprego, pois a empresa proporciona um salário legal para não ter possibilidade de procurar um outro serviço. (TE1)

E a gente tem um salário bom. (E2)

Destacou-se também como facilidade para uma assistência humanizada uma boa relação de comunicação com a liderança, uma acessibilidade de conseguir conversar e expor se tem algo que está incomodando o profissional, e de mostrar um outro ponto de vista e ser ouvido. 
As enfermeiras e os médicos ouvem muito a gente quanto "a eu acho que aquela criança ali está precisando de uma fisioterapia, está precisando mais passar um oleozinho no corpo”, então a gente tem essa facilidade aqui, de conversar e mostrar o nosso ponto de vista e ser ouvido. (TE3)

A colaboração e o comprometimento da equipe foram referidos pelos participantes como fator facilitador pois todos trabalham com o mesmo objetivo e tem um carinho muito grande por todas as crianças que passam pela UTIP.

Como nós abrimos a UTIP todos juntos, a equipe de enfermagem e a equipe médica, então todo mundo é bem coeso nessa parte da humanização. Eu acho que a nossa maior facilidade é a nossa equipe, que trabalham todos com o mesmo objetivo, tanto o turno do dia como o da noite em função de ter começado juntos. (E3)

Foi referido também a ajuda da brinquedoteca do hospital e os recursos disponíveis na UTIP como livros, brinquedos, DVDs, rádios com pendrive.

E nós temos também a ajuda de uma brinquedoteca e caso não tenha lá a gente também pede, a gente tem facilidades, é só correr atrás. Nós temos até um armário aqui, cheio de livros e brinquedos. Nós temos DVD, temos rádio com pendrive. (E2)

\subsection{Dificuldades encontradas pela equipe de enfermagem para garantir a assistência humanizada na UTIP}

As dificuldades existentes nas unidades hospitalares impedem que os profissionais prestem uma assistência humanizada aos pacientes, várias foram as dificuldades relatadas, mas alguns profissionais referiram não encontrar dificuldades para realizar a humanização no setor.

Eu não vejo dificuldades para prestar uma assistência humanizada. (E9)

Não acho que tenha dificuldade, aqui o pessoal foi moldado sabe, porque como é uma unidade recente, daí todos os profissionais antes de entrar conseguiram ter um treinamento, algo mais assim, ainda mais por ser criança a gente prioriza bastante. (TE6)

O pouco tempo e a falta de profissionais foram evidenciados como dificuldades, pois favorece a sobrecarga de trabalho e com isso a assistência humanizada acaba ficando um segundo plano.

As vezes a correria, porque você tem tanta coisa para fazer que você não tem um tempo para parar, para o olhar para o paciente e ver o que ele realmente está precisando. (TE2)

As dificuldades são mais em relação ao tempo, dos acontecimentos, pois se tem alguma urgência a gente não vai dar para o outro paciente um atendimento mais humanizado, as vezes com questão de gestão de pessoas, o número de funcionários, porque aí tu não consegues, você fica mais sobrecarregada, mais com relação a isso. (TE4)

A sobrecarga de trabalho, relatada em uma fala também se apresenta como uma dificuldade, pois o profissional fica muito concentrado em todas as obrigações que deve realizar e não tem tempo para prestar uma assistência humanizada ao paciente.

A prescrição, a folha de cuidados, os horários de tudo e acaba focando nisso e o tempo passa e você esquece de ver outros detalhes, é tu ter aquele padrão de ter que fazer os procedimentos em determinado horário, aquele número de medicações, número de procedimentos que você tem que dar conta e seguir aquilo e ficar focando só nisso e não olhar para o resto. (E4) 
A dificuldade mais relatada pelos profissionais foi em relação ao convívio com o país das crianças internadas. Na UTIP é liberado a presença de um familiar que pode ficar vinte e quatro horas por dia ao lado da criança. Para os profissionais os pais dificultam a assistência humanizada pois fazem muitos questionamentos e passam a impressão de não confiarem no profissional, não compreendem as condutas de saúde e muitas vezes tratam os mesmos com desrespeito.

Dificuldades em relação aos pais que as vezes não entendem o que a gente precisa fazer em relação ao filho, eles acham que a gente está judiando, que está maltratando, então até eles conseguirem colocar na cabeça que os procedimentos e as condutas que estão sendo tomadas, não é que ninguém quer judiar, ninguém quer maltratar, ninguém está aqui pra isso, as vezes tem país que tem uma certa resistência. (E5)

Não tem limites de até onde a família pode intrometer no trabalho, tudo elas questionam, o tempo inteiro, e sempre achando que a gente está fazendo alguma coisa errada, e acho que isso é um problema. E como a mãe fica aqui dentro o tempo inteiro, elas acabam se metendo em tudo [...] a gente acaba lidando com pessoas bem difíceis e a gente nunca tem a razão, a razão sempre é da família, a gente está sempre com medo, isso é um problema. (TE5)

A falta de espaço e conforto para os pais na UTIP se destacou como sendo um fator dificultador para garantir uma assistência humanizada, visto que muitos pais ficam durante longos períodos com os filhos internados na unidade.

A falta de espaço físico, porque dependendo a situação da criança, as vezes o pai e a mãe querem ficar junto só que não tem espaço, só tem espaço ali para um. A poltrona é confortável para uma noite, para mais de uma noite as pessoas começam a sentir dores nas costas, e tem pais que ficam meses dentro da UTIP, por morar longe, eles não trocam com outra pessoa, ficam sempre. Então, eu acho que todas as UTI deveriam ter um pouco mais de espaço e conforto. (TE7)

A UTIP é um setor onde são internadas crianças com estado de saúde graves e que necessitam de uma assistência mais complexa e de qualidade, os profissionais que ali atuam presam por um cuidado mais técnico. A assistência mecanicista foi uma das dificuldades relatadas para garantir um cuidado humanizado.

Eu acho que pela complexidade dos pacientes as vezes o nosso cuidado se torna mecânico, por a gente ter que prestar bastante pela qualidade, pela assistência mais técnica mesmo. (E8)

A UTIP é formada por uma equipe multiprofissional, na fala abaixo evidenciou a falta de uma boa comunicação com a equipe médica e uma falta de organização com a equipe multiprofissional, esses fatores dificultam uma assistência de qualidade e humanizada aos pacientes.

E também um pouco pela falta de troca de comunicação com a equipe médica, que os cuidados as vezes são muito impostos e não compartilhados, não tem uma coparticipação de todos para o planejamento do cuidado do paciente, é bastante técnico mesmo. Precisaria ter mais rounds com uma equipe multiprofissional mesmo, com terapeuta ocupacional, fonoaudióloga, fisioterapeuta, todo mundo pudessem conversar juntos para planejar um cuidado para o paciente mais singular. (E8)

\section{Discussão}

Sobre as facilidades para garantir uma assistência humanizada verificou-se que há fatores que favorecem a realização da assistência humanizada que pela equipe de enfermagem. O fato da Unidade ter poucos pacientes (no máximo 10), ser uma unidade pequena, ter uma boa carga horária e o fato de cada profissional ficar com apenas uma criança comparado a outros setores foram referidos pelos participantes como facilitadores para a realização de uma assistência humanizada. $\mathrm{O}$ atendimento humanizado faz-se presente quando o local de trabalho conta com um quantitativo suficiente de pessoas nos afazeres do setor, evitando a sobrecarga de trabalho e assegurando a qualidade do serviço (Rodrigues \& Calegari, 2016). 
Outra facilidade destacada pela maioria dos profissionais é o trabalho com uma equipe multidisciplinar, formada por fisioterapeutas, fonoaudiólogos, nutricionistas, terapeutas ocupacionais, psicólogos, médicos e enfermeiras. Essa equipe faz com que o cuidado seja integral e que a assistência se torne mais humanizada dentro da UTIP. Destacaram que a troca de experiências entre os membros da equipe favorece a humanização da assistência no setor. No cenário da prática, é possível observar uma auto-organização estrutural das UTI, tanto na composição do ambiente como na área de recursos humanos, formada por equipes multiprofissionais especializadas que, integradas aos avanços tecnológicos, possibilitam melhorar a qualidade e a segurança da assistência prestada (Medeiros et al., 2016).

A remuneração salarial boa foi referida pelos participantes como um fator facilitador, pois faz com que os profissionais tenham apenas um emprego e não tenham interesse em procurar outro serviço. Para o profissional realizar uma assistência de qualidade e humanizada é fundamental que o mesmo tenha boas condições de trabalho, que valorize sua categoria e tenha uma remuneração justa para que não seja preciso submeter-se a dois empregos ou mais e a uma carga horária semana de trabalho excessiva (Souza-Júnior et al, 2015).

Destacou-se também como facilidade para uma assistência humanizada uma boa relação de comunicação com a liderança, uma acessibilidade de conseguir conversar e expor se tem algo que está incomodando o profissional, e de mostrar um outro ponto de vista e ser ouvido. A gestão participativa merece destaque nessa discussão, a própria PNH prevê, nas suas estratégias gerais, a promoção de ações que levem à participação dos trabalhadores nas decisões em saúde, para que estes se sintam partícipes do processo. Traduz-se então, em um trabalho coletivo em busca de ações planejadas, estratégicas e resolutivas, implicando, dessa forma, em uma melhor qualidade da gestão e, por conseguinte, da atenção (Nascimento et al., 2017).

A colaboração e o comprometimento da equipe foram referidos pelos participantes como fator facilitador, pois todos trabalham com o mesmo objetivo e tem um carinho muito grande por todas as crianças que passam pela UTIP. O trabalho em equipe também é uma estratégia de organização da humanização, que se traduz em qualidade na atenção integral às necessidades das pessoas assistidas. Portanto, os enfermeiros e os técnicos de enfermagem devem valorizar o trabalho em equipe como estratégia de interação para o cuidado à criança hospitalizada (Pereira et al., 2018).

Foi referido também a ajuda da brinquedoteca do hospital e os recursos disponíveis na UTIP como livros, brinquedos, DVDs, rádios com pendrive. O brincar no contexto da hospitalização infantil tem como objetivo diminuir o estresse, liberar a afetividade e expor as emoções da criança internada, mostrando-se como uma estratégia eficaz, pois a criança libera sua criatividade, recria o mundo e explora seus limites. Salienta-se que, a ludoterapia possibilita que a permanência da criança internada seja menos dolorosa, reconhecendo seus medos e trabalhando seus sentimentos de uma forma que a induza a exprimir preocupações, entender momentos de estresse ou novas aprendizagens e, dessa maneira, fortalecer a realização do tratamento (Falke et al, 2018).

Quanto às dificuldades encontradas para garantir uma assistência humanizada verificou-se que as dificuldades existentes nas unidades hospitalares impedem que os profissionais prestem uma assistência humanizada aos pacientes, várias foram as dificuldades relatadas, mas alguns profissionais referiram não encontrar dificuldades para realizar a humanização no setor. O pouco tempo e a falta de profissionais foram evidenciados como dificuldades, pois favorece a sobrecarga de trabalho e com isso a assistência humanizada acaba ficando um segundo plano. As atividades intensas que o enfermeiro executa na UTI podem conferir pouco tempo para um contanto humano mais íntimo com o paciente (De Moraes et al., 2017).

A gestão de pessoas na área da enfermagem, em instituições hospitalares é importante para garantir os recursos humanos, suficientes e competentes, para a manutenção da qualidade da assistência e desenvolvimento das atividades laborais de enfermagem, sendo fundamental que os gerentes de enfermagem participem ativamente do processo de gestão de pessoas, 
evitando a sobrecarga de trabalho proporcionando, consequentemente, um aumento da segurança do paciente (Michelan; Spiri, 2018).

A sobrecarga de trabalho, relatada em uma fala também se apresenta como uma dificuldade, pois o profissional fica muito concentrado em todas as obrigações que deve realizar e não tem tempo para prestar uma assistência humanizada ao paciente. Se a demanda de trabalho é alta e em contrapartida a mão de obra é escassa, a condição do atendimento será prejudicada. Por mais que se atenda a todos, certamente, nem todas as necessidades serão atendidas, cooperando para o caos que se vive no serviço público de saúde, o qual ainda precisa avançar muito para assegurar os princípios do SUS, bem como a humanização da assistência (Nascimento et al., 2017).

Em um ambiente de trabalho como o hospitalar, a comunicação seja verbal ou não-verbal faz parte do processo de cuidar em enfermagem, uma vez que potencializa a interação entre a equipe, os pacientes e familiares, por isso precisa ser conduzida com ética e zelo a fim de tornar as relações humanas mais harmônicas. (Baggio, 2007)

Dentre as dificuldades apontadas pelos profissionais de enfermagem para a prestação de uma assistência humanizada destacam-se aqueles referentes à sobrecarga de trabalho em virtude da quantidade insuficiente de profissionais para atender a demanda existente (De Moraes et al., 2017). Sabe-se que a qualidade do cuidado não é garantida somente pela qualificação de seus profissionais, mas também pela quantificação destes para o desenvolvimento das atividades legalmente previstas (Medeiros et al., 2016).

A dificuldade mais relatada pelos profissionais foi em relação ao convívio com o país das crianças internadas. Na UTIP é liberada a presença de um familiar que pode ficar vinte e quatro horas por dia ao lado da criança. Para os profissionais os pais dificultam a assistência humanizada, pois fazem muitos questionamentos e passam a impressão de não confiarem no profissional, não compreendem as condutas de saúde e muitas vezes tratam os mesmos com desrespeito. Ao mesmo tempo, embora os profissionais reconheçam a importância de presença da família junto ao paciente, na prática, muitas vezes, ela é vista como um entrave para a manutenção das rotinas nas UTIP (Machado \& Soares, 2016).

A falta de espaço e conforto para os pais na UTIP se destacou como uma dificuldade para garantir uma assistência humanizada, visto que muitos pais ficam durante longos períodos com os filhos internados na unidade. A UTIP promove o acompanhamento dos pais à criança durante seu período de internação, sendo um direito garantido. Contudo, em alguns hospitais a infraestrutura prejudica o acompanhamento. Deste modo, são necessárias estratégias visando viabilizar a permanência dos pais com maior conforto (De Morais, 2017).

A UTIP é um setor onde são internadas crianças com estado de saúde graves e que necessitam de uma assistência mais complexa e de qualidade, os profissionais que ali atuam presam por um cuidado mais técnico. A assistência mecanicista foi uma das dificuldades relatadas para garantir um cuidado humanizado. Verifica-se que em muitas UTIP ainda prevalece o cuidado técnico positivista. A complexidade da assistência no ambiente da UTIP ainda se concentra na alta tecnologia, com a finalidade de satisfazer primeiro as necessidades biológicas dos pacientes, caracterizando outra dificuldade em proporcionar um cuidado humanizado (Ribeiro et al., 2016).

A UTIP é formada por uma equipe multiprofissional. A falta de uma boa comunicação com a equipe médica e a falta de organização da equipe são fatores dificultadores de uma assistência de qualidade e humanizada aos pacientes. A falta de informações também e um problema a ser identificado pelos trabalhadores de enfermagem sobre os agentes de riscos peculiares ao ambiente de trabalho. Desta forma, estratégias que favoreçam a transferência segura de informações nas trocas de plantões, também se mostram necessárias, para uma melhor condição de trabalho bem como segurança ao paciente (Michelan \& Spiri, 2018).

As relações interpessoais no trabalho, tanto entre a equipe de enfermagem quanto entre a multiprofissional quando não se desenvolvem satisfatoriamente, produzem um ambiente de trabalho desfavorável que interfere em todo o processo 
laboral, gera insatisfação no profissional, e, em consequência, dificultam a humanização entre os trabalhadores (Martins et al., 2015).

\section{Conclusão}

O estudo objetivou conhecer as facilidades e dificuldades da equipe de enfermagem na prestação de um cuidado humanizado na Unidade de Terapia Intensiva Pediátrica. Os participantes citaram como facilidades para garantir uma assistência humanizada o reduzido número de pacientes do setor, o trabalho em equipe multidisciplinar, a boa remuneração e a boa comunicação com a liderança, a colaboração e o comprometimento da equipe e ter uma brinquedoteca no hospital. Como dificuldades referiram, alguns referiram que não existem, o pouco tempo e falta de profissionais, a sobrecarga de trabalho, o convívio com o país das crianças internadas, a falta de espaço e conforto para os pais na unidade, a prestação de um cuidado mais técnico e de uma assistência mecanicista e as dificuldades individuais de cada pessoa em trabalhar com crianças em estado crítico.

Os dados possibilitaram concluir que a assistência de enfermagem na UTIP é complexa. Para a equipe o conceito de humanização da assistência é amplo e contempla tanto a criança quanto a família.

Apesar das facilidades citadas pelos profissionais, sendo a principal ser a humanização parte da política do HU, ainda há muitas dificuldades a serem superadas. Os profissionais precisam enfrentar o desafio de atuarem com crianças em estado crítico e seus pais, minimizando seu sofrimento, qualificando a assistência e sendo parte de sua rede de apoio neste momento. Precisa haver um esforço no sentido de melhorar a estrutura física da unidade de forma garantir o conforto para a permanência da família nas 24 horas do dia de forma que esta não se constitua como elemento de desumanização. Concluiu-se que a humanização da assistência faz parte da preocupação dos profissionais atuantes na unidade. A equipe de enfermagem considera a pratica humanizada na UTIP importante, enfrentando desafios para cuidar a criança em estado crítico e sua família.

Como limitações encontradas neste estudo, o fato de ser sido realizado em um único contexto e apenas com a equipe de enfermagem. Sugere-se que sejam realizados outros estudos que contemplem outros contextos de UTIP, englobando toda equipe multiprofissional que faça parte do setor, para que seja possível conhecer outros cenários e que possam ser explorados outras formas e estratégias assistenciais de atuação frente a humanização da criança e seus familiares diante de uma internação hospitalar.

\section{Referências}

Baggio, M. A. (2007). Relações humanas no ambiente de trabalho: o (des) cuidado de sido profissional de enfermagem. Revista Gaúcha de Enfermagem, 28 (3), 409-409. http://seer.ufrgs.br/RevistaGauchadeEnfermagem/article/view/4695/259.

Bardin, L. (2011). Análise de conteúdo (70a ed.), Almedina Brasil.

Brasil (2017). Portaria de Consolidação no 3/GM/MS, de 28 de setembro de 2017. Consolidação das normas sobre as redes do Sistema Único de Saúde. Brasília, DF: Presidência da República. http://bvsms.saude.gov.br/bvs/saudelegis/gm/2017/prc0003_03_10_2017.html.

Brasil (2016). Resolução no 510, de 7 de abril de 2016. Dispõe sobre as normas aplicáveis a pesquisas em Ciências Humanas e Sociais. Diário Oficial da União.

Falke, A. C. S., Milbrath, V. M., \& Freitag, V. L. (2018). Percepción del equipo de enfermería sobre el enfoque lúdico al niño hospitalizado. Cultura de los cuidados, (50), 12-24.

Gequelin, J. et al. (2014). Percepção de acompanhantes sobre a criança intubada em UTI Pediátrica. Cogitare Enfermagem, 19(3). 483-90. https://revistas.ufpr.br/cogitare/article/viewFile/33434/23219.

Guerra, C. M.; Chesani, F. H.; Bossardi, C. N. (2019). Unidade de terapia intensiva pediátrica: visão da criança sobre o processo de internação. Revista Univap, 25 (48) p. 176-188. Unidade de terapia intensiva pediátrica: visão da criança sobre o processo de internação | revista univap. http://dx.doi.org/10.18066/revistaunivap.v25i48.2205.

Machado, E. R.\& Soares, N. V. (2016). Humanização em UTI: sentidos e significados sob a ótica da equipe de saúde. Revista de Enfermagem do Centro-Oeste Mineiro, 6 (3). 2342-2348. http://www.seer.ufsj.edu.br/index.php/recom/article/view/1011. http://seer.ufsj.edu.br/index.php/recom/article/view/1011. 
Martins, J. T. et al. (2015) Humanização no processo de trabalho na percepção de enfermeiros de unidade de terapia intensiva. Cogitare Enfermagem, 20 (3). 589-595. https://pdfs.semanticscholar.org/a307/cf42277ea326fc950676e0bf206dc96da42e.pdf. https://revistas.ufpr.br/cogitare/article/view/41521.

Medeiros, R. M. K., Teixeira, R. C., Nicolini, A. B., Alvares, A. S., Corrêa, Á. C. D. P., \& Martins, D. P. (2016). Cuidados humanizados: a inserção de enfermeiras obstétricas em um hospital de ensino. Revista Brasileira de Enfermagem, 69, 1091-1098.

Menezes, M. A criança e sua rede familiar: significações do processo de hospitalização. (Tese de Doutorado), Universidade Federal de Santa Catarina, Florianópolis, SC, BRASIL (2010). A Criança e sua rede familiar: significações do processo de hospitalização (ufsc.br). 1-411. https://repositorio.ufsc.br/handle/123456789/103271.

Michelan, V. C. A. \& Spiri, W. C. (2018). Percepção da humanização dos trabalhadores de enfermagem em terapia intensiva. Revista Brasileira de Enfermagem, 71, 372-378. https://www.scielo.br/j/reben/a/dFxvZ3XkkhzxJLRGZF3xZyR/?lang=pt. https://www.scielo.br/j/reben/a/dFxvZ3XkkhzxJL RGZF3xZyR/?lang=pt\&format=html.

Minayo, M. C. S. (vozes). (2010) Pesquisa Social; teoria, método e criatividade. (29 ed.). Vozes.

de Moraes, A. M. M., da Silva Barros, A. C., de Oliveira, A. V., Cardoso, D. P. D. C., dos Reis Gonçalves, F. I., Torres, J. B., \& do Santos, T. L. (2017). Importância da assistência de enfermagem humanizada. Revista Eletrônica Acervo Saúde/Electronic Journal Collection Health. 735 -741.

Nascimento, F. G. P. \& Silva, V. R. (2017). Importância da visita à criança em unidade de terapia intensiva pediátrica: opinião dos acompanhantes. Revista de Enfermagem UFPE on line, 11(10), 3920-3927. https://periodicos.ufpe.br/revistas/revistaenfermagem/article/view/25367. https://periodicos.ufpe.br/revistas/revistaenfermagem/article/viewFile/25367/pdf.

Pêgo, C. O. \& Barros, M. M. A. (2017). Unidade de Terapia Intensiva Pediátrica: expectativas e sentimentos dos pais da criança gravemente enferma. Rev. bras. ciênc. saúde, 11-20. (bvsalud.org). https://pesquisa.bvsalud.org/portal/resource/pt/biblio- 965439.

Pereira, C. R. et al. (2018). A humanização da assistência de enfermagem à criança hospitalizada: uma revisão integrativa. Revista Intercâmbio, 11, 70-85. http://www.intercambio.unimontes.br/index.php/intercambio/article/view/224. http://www.intercambio.unimontes.br/index.php/intercambio/article/view/224.

Pozzatti, R. et al. (2017). Enfrentamento da internação da criança em UTI-Ped pelo familiar/cuidador. Disciplinarum Scientia| Saúde, 18 (1), 157-168. Enfrentamento da internação da criança em UTI-Ped pelo familiar/cuidador | Pozzatti | Disciplinarum Scientia | Saúde (ufn.edu.br). https://enade.unifra.br/index.php/disciplinarumS/article/view/2259.

Pontes, E. P. et al. (2014). Comunicação não verbal na unidade de terapia intensiva pediátrica: percepção da equipe multidisciplinar. Revista Mineira de Enfermagem, 18 (1), 152-163. http://www.reme.org.br/artigo/detalhes/915.

Ribeiro, K. R. A. et al. (2017) Dificuldades encontradas pela enfermagem para implementar a humanização na unidade de terapia intensiva. Rev. enferm. UFPI, 51- 56, https://revistas.ufpi.br/index.php/reufpi/article/view/5777. https://pesquisa.bvsalud.org/portal/resource/fr/biblio-1033929.

Rodrigues, A. C.\& Calegari, T. (2016). Humanização da assistência na unidade de terapia intensiva pediátrica: perspectiva da equipe de enfermagem. Revista Mineira de Enfermagem, 20. Humanização da assistência na unidade de terapia intensiva pediátrica: perspectiva da equipe de enfermagem. REME rev. min. enferm. http://www.gnresearch.org/doi/10.5935/1415- 2762.20160003.

Sampaio, A. A. et al. (2017). Cuidado centrado na família em unidade de terapia intensiva pediátrica: percepção dos profissionais. Rev Rene, 18 (4), 515-520. Cuidado centrado na família em unidade de terapia intensiva pediátrica: percepção dos profissionais. Rev Rene (ufc.br). https://www.redalyc.org/jatsRepo/3240/324053756013/324053756013.pdf

Santos, E. L. et al. (2018). Assistência humanizada: percepção do enfermeiro intensivista. Revista Baiana de Enfermagem, 32: e23680 Disponível em: https://www.researchgate.net/publication/324881915_ASSISTENCIA_HUMANIZADA_PERCEPCAO_DO_ENFERMEIRO_INTENSIVISTA. https://cienciasmedicasbiologicas.ufba.br/index.php/enfermagem/article/view/23680.

Santos, P. M. et al. (2020). A percepção da criança hospitalizada quanto ao ambiente da unidade de terapia intensiva pediátrica. Revista de Iniciação Científica e Extensão, 3 (1), 331-40. A percepção da criança hospitalizada quanto ao ambiente da unidade de terapia intensiva pediátrica - DOAJ. https://revistasfacesa.senaaires.com.br/index.php/iniciacao- ientifica/article/view/19.

Sossela, C. R. \& Sager, F. (2017). A criança e o brinquedo no contexto hospitalar. Revista da SBPH, 20 (1), 17-31. http://pepsic.bvsalud.org/scielo.php?script=sci_arttext\&pid=S1516-08582017000100003\#: :text=RESUMO.\%20O\%20brincar\%20\%C3\%A9\%20 um\%20d ireito\%20essencial\%20para,avaliar\%20as\%20consequ\%C3\%AAncias\%20da\%20utiliza\%C3\%A7\%C3\%A3o\%20de\%20diferentes\%20. http://pepsic.bvsalud .org/scielo.php?script=sci_ar ttext\&pid=S151608582017000100003

Souza-Júnior, P. R. B. D., Freitas, M. P. S. D., Antonaci, G. D. A., \& Szwarcwald, C. L. (2015). Desenho da amostra da Pesquisa Nacional de Saúde 2013. Epidemiologia e Serviços de Saúde, 24, 207-216.

Villa, L. L. O. et al. (2017). A percepção do acompanhante sobre o atendimento humanizado em unidade de terapia intensiva pediátrica. Rev. pesqui. cuid. fundam. (Online), 187-192. https://pesquisa.bvsalud.org/portal/resource/pt/biblio-836325. https://dialnet.unirioja.es/servlet/articulo?codigo=5800033. 